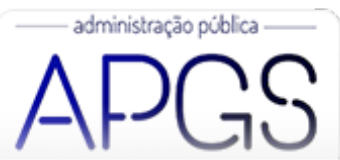

Administração Pública e Gestão Social ISSN: 2175-5787

apgs@ufv.br

Universidade Federal de Viçosa

Brasil

\title{
Influência da Socialização Organizacional sobre o Comprometimento Organizacional: Um Estudo de Caso na Polícia Militar de Sergipe
}

Nunes dos Santos, Daiane; Rosana Melo de Araújo, Marley; Cavalcanti Marques, Erika

Influência da Socialização Organizacional sobre o Comprometimento Organizacional: Um Estudo de Caso na

Polícia Militar de Sergipe

Administração Pública e Gestão Social, vol. 12, núm. 4, 2020

Universidade Federal de Viçosa, Brasil

Disponible en: http://www.redalyc.org/articulo.oa?id=351564289016

Esta obra está bajo una Licencia Creative Commons Atribución-NoComercial-SinDerivar 3.0 Internacional. 


\title{
Influência da Socialização Organizacional sobre o Comprometimento Organizacional: Um Estudo de Caso na Polícia Militar de Sergipe
}

\author{
The Influence of Organizational Socialization on Organizational Commitment: A Case Study in the Military Police \\ of Sergipe \\ La Influencia de la Socialización Organizacional sobre el Compromiso Organizacional: Un Estudio de caso en la \\ Policia Militar de Sergipe
}

Daiane Nunes dos Santos

Universidade Federal de Sergipe, Brasil

Redalyc: http://www.redalyc.org/articulo.oa?

daianenunesufs@gmail.com

Marley Rosana Melo de Araújo

Universidade Federal de Sergipe, Brasil

marleymeloaraujo@gmail.com

Erika Cavalcanti Marques

Universidade Federal de Sergipe, Brasil

ecmar@hotmail.com id $=351564289016$

\section{Resumo:}

Esta pesquisa analisou a influência da socialização organizacional sobre o comprometimento organizacional de policiais militares do Estado de Sergipe. Foram aplicados o Inventário de Socialização Organizacional (ISO), a Escala de Comprometimento Organizacional e uma ficha de dados sociodemográficos a uma amostra de 270 policiais. Realizada análise fatorial exploratória do ISO, obteve-se estrutura interna constituída por três fatores (Integração à organização - IORG; Domínio de procedimentos e atividades - DPA; Proatividade e competência - P\&C). Quanto ao comprometimento, os resultados indicaram excelente índice de confiabilidade para a escala utilizada, a qual se constitui por bases afetiva, instrumental e normativa. A análise de regressão múltipla apontou os fatores IORG e P\&C como variáveis preditivas dos comprometimentos afetivo e normativo, ainda que não tenha comparecido determinação sobre o instrumental. Sintetizando, são a socialização cultural (capitaneada pela instituição) e a socialização movida pelo próprio indivíduo que produzem efeito sobre os vínculos positivos com a organização de trabalho.

PalaVras-CHAVE: Socialização organizacional, comprometimento organizacional, polícia militar.

\section{Abstract:}

This research analyzed the influence of organizational socialization on the organizational commitment of military police officers of the state of Sergipe, in the Northeast Region of Brazil. The Organizational Socialization Inventory (ISO), the Organizational Commitment Scale and a socio-demographic data sheet were applied to 270 police officers. An exploratory factorial analysis of the ISO was performed, an internal structure was constituted by three factors (IORG, Domain of procedures and activities - DPA, Proactivity and competence - P \& C). Regarding the commitment, the indicators were used in relation to the degree of confidence for a scale used, as it is by affective, instrumental and normative bases. Multiple regression analysis pointed out the IORG and P \& $C$ factors as predictive variables of affective and normative commitment, although there was no determination on the instrumental. Summarizing, the cultural socialization (captained by the institution) and the socialization moved by the individual himself that had an effect on the positive links with the work organization.

KEYWORDS: Organizational socialization, organizational commitment, military police.

\section{RESUMEN:}

Esta investigación analizó la influencia de la socialización organizacional en el comportamiento organizacional de policías militares del estado de Sergipe, situado em la Región Nordeste de Brasil. Fueron aplicados el Inventario de Socialización Organizacional 
(ISO), la Escala de Comprometimiento Organizacional y una ficha con dados demográficos a 270 policías. Después de realizar un análisis factorial exploratorio del ISO, se obtuvo una estructura interna constituida por tres factores (Integración a la organización IORG; Dominio de procedimientos y actividades - DPA; Proactividad y competencia - P\&C). Al respecto del comprometimiento, los resultados presentaron un excelente índice de confiabilidad para la escala utilizada, la cual se constituye de una base afectiva, una instrumental y una normativa. La análisis de regresión múltiple apuntó los factores IORG y P\&C como variables predictivas de los comprometimientos afectivos y normativos, aunque no haya predecido la dimensión instrumental. Resumiendo, la socialización cultura (comandada por la institución) y la socialización movida por el propio individuo producen efectos sobre los vínculos positivos con la organización del trabajo.

Palabras Clave: Socialización organizacional, compromiso organizacional, policia militar.

\section{INTRODUÇão}

Realizado um processo seletivo, seja em empresa privada ou em instituição pública, após os trâmites admissionais, eis que surge o primeiro dia de trabalho do funcionário recém-admitido. Quanto mais minucioso for um processo de recrutamento e seleção de pessoal, como também as etapas de um concurso público, maior a probabilidade de a área responsável por esses processos ser assertiva na busca de congruência entre os valores, interesses e necessidades do funcionário e aqueles da organização. Ambos precisam adaptarse um ao outro para manterem essa assertividade e corresponderem no que buscam mutuamente, porém, o que se percebe é que a cobrança por adaptação é comumente dirigida ao funcionário.

A seleção de pessoal tem como objetivo admitir pessoas para serem bem sucedidas no trabalho. Assim, é importante que as ações da área de Gestão de Pessoas, após um processo seletivo, contribuam para os ajustes da organização ao funcionário e deste à organização e às atividades que desenvolverá. Criar um espaço de acolhimento no momento em que o funcionário se insere em um novo contexto organizacional, um espaço de diálogo sobre essa nova situação, sobre seus sentimentos iniciais no trabalho e perspectivas para o futuro, ou seja, fomentar um clima de recepção, compreensão e aceitação do novo, é um trabalho fundamental de quem atua na área de Gestão de Pessoas nas organizações (Cardozo, Arriero, Mariani, Araújo, \& Arruda, 2018).

A socialização organizacional é um fenômeno processual, de participação de um indivíduo em um grupo, fenômeno dinâmico e contínuo, que assume relevância para as organizações, uma vez que trata diversos aspectos fundamentais para sua sustentação interna (Carvalho, Borges, Vikan, \& Hjemdal, 2011). Este fenômeno trata da redução de incertezas e da busca pela inserção assertiva dos funcionários ao trabalho, da manutenção da cultura organizacional ou foco nas metas a serem alcançadas, a depender da estratégia eleita pela organização para socializar seus novos membros, e de outros aspectos durante a vida laboral dos indivíduos (Cardozo, Araújo, \& Mariani, 2017; Cardozo et al., 2018; Cooper-Thomas, Paterson, Stadler, \& Saks, 2014; Woodrow \& Guest, 2017)

O comprometimento organizacional, um dos temas atualmente mais investigados no campo microorganizacional (Bastos, Maia, Rodrigues, Macambira, \& Borges-Andrade, 2014), também é considerado um fenômeno de relevância para as organizações, ainda que estudos tenham apontado dificuldade de consenso acerca de sua estrutura (Paiva, Dutra, \& Luz, 2015). Há autores, como Mowday, Steers e Porter (1979), que compreenderam o fenômeno como um construto unidimensional, isto é, um vínculo de natureza atitudinal-afetiva entre o trabalhador e a organização, em que o indivíduo desenvolve identificação com a organização de trabalho e seus objetivos. Outros autores, como Meyer e Allen, preconizam a perspectiva tridimensional, incluindo os componentes afetivo, de continuação e normativo (Bastos, Pinho, Aguiar, \& Menezes, 2011; Bastos et al., 2014). É de se esperar que uma pessoa que se perceba integrada à cultura de uma organização, aos seus membros integrantes e às suas rotinas laborais, se sinta mais comprometida, expectativa esta que integra as ações de sistemas de recursos humanos (RH) dirigidas a socializar novos funcionários, incentivada por pesquisadores que identificam o papel do contexto organizacional na formação e desenvolvimento do comprometimento (Bastos et al., 2014). 
A cultura de uma organização militar possui especificidades inexistentes em outras culturas organizacionais, uma vez que há a necessidade de adesão aos princípios ideológicos da doutrina militar, a exemplo de obediência à hierarquia, disciplina e espírito de equipe, configurando um rito de passagem operacionalizado por vários recursos de socialização. A socialização organizacional dos novos policiais militares, por exemplo, compreende práticas institucionais e individuais voltadas para a socialização técnica, ou seja, para o aprendizado de conhecimentos e habilidades técnicas, sobre o cotidiano de trabalho e sobre o desempenho do papel de policial, e voltadas para a socialização cultural, especialmente para que se construa uma identidade profissional de policial militar, por meio da apreensão de valores e normas para o trabalho e valores e crenças sobre o papel policial (Poncioni, 2005). Cabe indagar se a efetiva socialização de novos trabalhadores aos elementos constituintes de uma instituição militar responderia por um maior comprometimento organizacional destes indivíduos.

Pesquisas sobre socialização e comprometimento organizacional trouxeram grandes contribuições, tanto no sentido de esclarecimento acerca dos construtos, quanto à disponibilização de instrumentos de medida válidos e consistentes (Allen, Eby, Chao, \& Bauer, 2017; Moyson, Raapshorst, Groeneveld, \& Van de Walle, 2018; Saks \& Gruman, 2018). No que se refere à investigação destes fenômenos no contexto das organizações militares ou organizações policiais, as pesquisas (Dick, 2011; Rodrigues \& Bastos, 2013; Wortmeyer, 2007) se dedicaram a entendê-los isoladamente, ou seja, concentraram-se em compreender ou os processos de socialização organizacional, ou os de comprometimento, de modo que se observa uma carência de estudos que investiguem a natureza correlacional desses fenômenos nesse contexto organizacional em específico. Reflexões sobre a gestão do comprometimento nas organizações de trabalho apresentam lacunas ligadas aos impactos e à efetividade das práticas organizacionais e de gestão de pessoas, a exemplo da socialização organizacional, nos níveis de comprometimento dos empregados (Bastos et al., 2014), daí a importância de mais estudos que correlacionem estes dois fenômenos, principalmente em organizações como a Polícia Militar (PM), nas quais os indivíduos precisam estar comprometidos para resistir às adversidades e periculosidade da atividade profissional (Wortmeyer, 2007). A fim de preencher esta lacuna e apresentar à comunidade científica e aos profissionais que atuam no campo organizacional evidências acerca dessa relação, o presente estudo teve como objetivo geral analisar a influência da socialização organizacional sobre o comprometimento organizacional dos servidores de unidades especializadas da Polícia Militar do Estado de Sergipe (PM-SE). Entre os objetivos específicos, buscou-se: Identificar a percepção de servidores da PM-SE sobre o seu grau de socialização organizacional; identificar a magnitude e preponderância das três dimensões do comprometimento organizacional declarado pelos servidores; testar o poder preditivo da socialização organizacional sobre o comprometimento organizacional. Para tanto, inicialmente, serão apresentados os fundamentos teóricos que embasaram este estudo, incluindo aspectos acerca dos processos de socialização e comprometimento organizacionais. Em seguida, serão esclarecidos os procedimentos metodológicos, entre eles, a caracterização da amostra, os instrumentos utilizados e procedimentos de coleta e análise dos dados. Posteriormente, serão detalhados os resultados obtidos, bem como a discussão destes. Por fim, serão apresentadas as considerações finais, incluindo as limitações do estudo e seus principais achados.

Estudos desta natureza propiciam maior compreensão sobre fenômenos aplicados ao comportamento organizacional, possibilitando aos profissionais da área recursos críticos para o planejamento de programas de gestão de pessoas que visem à eficácia organizacional e à qualidade de vida no trabalho. Igualmente, trazem evidências acadêmicas adicionais para entender o funcionamento de organizaçóes militares, ainda pouco estudadas, em função de seu acesso limitado para pesquisadores.

\section{FUNDAMENTOS TEÓRICOS}

Os funcionários de uma empresa convivem em uma sociedade organizacional com crenças, rituais, maneiras de sentir, pensar e agir consideradas corretas dentro destas organizações, configurando a particularidade de 
sua cultura corporativa. A cultura organizacional é um conjunto de mecanismos que buscam o controle das situações e comportamentos através de planos e regras. É na cultura organizacional que os funcionários de uma empresa encontram orientações que conduzem o seu comportamento (Silva \& Zanelli, 2004).

A cultura organizacional é uma associação de pressupostos básicos de um grupo quanto ao manejo e resolução de problemas de adaptação externa e de integração entre os seus membros. $O$ processo de construção de uma cultura organizacional é um aprendizado coletivo, no sentido de se adaptar às exigências internas e externas. Uma vez apreendidas as formas de comportamento que levam ao êxito no enfrentamento das situações vivenciadas no ambiente organizacional, passam-se a reutilizá-las e a compartilhá-las entre os membros como modo assertivo de posicionamento cognitivo, afetivo e comportamental diante de situações e problemas semelhantes (Cardozo et al., 2018). É dentro da cultura organizacional que os processos de socialização são moldados, a fim de equilibrar os interesses da organização e do novo funcionário contratado. A socialização organizacional promove a assimilação de valores, normas, crenças e práticas inerentes à cultura da instituição da qual o novo empregado fará parte (Genari, Ibrahim, \& Ibrahim, 2017).

\subsection{Socialização Organizacional}

A socialização organizacional tem sido enfocada como um processo de aprendizagem que ocorre toda vez que um indivíduo vivencia mudanças de status ou papel em uma organização. Para o ajustamento a um novo papel, torna-se necessário desenvolver conhecimentos, habilidades e atitudes, assim como assimilar valores, crenças, normas e práticas característicos da cultura organizacional (Wortmeyer, 2007). A socialização organizacional, um aspecto que também assume sua importância para a organização e para o funcionário recém-admitido, pode iniciar ainda na fase de recrutamento e seleção de pessoas e perpassar processos de treinamento e demais processos da área de Gestão de Pessoas que venham a contribuir para a inserção e integração do novo funcionário em um contexto organizacional (Genari et al., 2017).

Alguns fatores têm sido considerados significativos para a integração do indivíduo à organização e seu envolvimento com o trabalho desempenhado, tais como personalidade (pessoas que dão ênfase à virtude do trabalho, que creem que podem controlar os eventos de sua vida, têm autoestima elevada e necessidade de crescimento satisfeita pelo trabalho), características do cargo (autonomia para realizar atividades, tendo estas um significado para o indivíduo ao passo que o desafiam, exigindo diversas habilidades), características dos líderes (consideração com as relações interpessoais, espaço para participação dos trabalhadores em processos de decisão e preocupação com o processo de comunicação com seus liderados) e os papéis organizacionais (percepção de conflitos e ambiguidade de papéis organizacionais) (Siqueira \& Gomide, 2004).

A socialização organizacional é um processo que tem continuidade por toda a vida laboral do indivíduo (Borges \& Albuquerque, 2014). Trata-se de um processo pelo qual os novos funcionários aprendem sobre os valores, normas, expectativas e procedimentos estabelecidos, a fim de assumirem papéis específicos e tornarem-se membros aceitos pelo grupo ou pela organização (Cooper-Thomas et al., 2014). A socialização organizacional contribui para o esclarecimento sobre as expectativas do grupo (equipe de trabalho e organização), o que pode auxiliar na redução da insegurança inicial em sua entrada na empresa. Quanto à organização, pode refletir um desejo de que haja entendimento acerca de sua estrutura, metas e filosofia, visando ainda à redução do surgimento de conflitos, à apresentação de procedimentos e técnicas de trabalho, à redução de falhas e retrabalho, de custos e tempo gasto nas atividades (Bowditch \& Buono, 2002).

No setor público, algumas pesquisas foram realizadas a fim de entender a socialização organizacional (Miranda, Capelle, Mafra, \& Moreira, 2015; Oliveira et al., 2008; Rosa \& Brito, 2010). Esses estudos destacam que a principal diferença na socialização entre as instituições públicas e privadas diz respeito ao processo de inserção de seus membros na organização, de modo que, no setor público, este se dá através de concurso público. No contexto das corporações militares, o processo de socialização é atravessado pela premissa de transformação de um civil em um militar, considerado um rito de passagem. Essa iniciação à 
cultura militar é realizada, inicialmente, através do curso de formação de soldados, apresentando um caráter formal, expresso nas regras básicas disciplinares da organização militar, nos procedimentos burocráticos e nas normas disciplinares. A socialização nesse grupo envolve uma série de práticas pedagógicas de caráter coletivo que visam ao despojamento dos valores civis e ao pertencimento dentro e fora da organização (Rosa \& Brito, 2010).

O processo de socialização organizacional é um fenômeno que pode estar diretamente ligado ao comprometimento do indivíduo com a organização, estabelecendo uma relação de antecedência a este último. Compreender como o indivíduo passa a sentir-se vinculado à organização de trabalho e como o processo de socialização organizacional colabora para esse comprometimento tem sido de fundamental relevância para aperfeiçoar as práticas organizacionais.

\subsection{Comprometimento Organizacional}

Todas as pessoas são capazes de desenvolver suas próprias percepções, afetos, propósitos acerca do trabalho ou sobre questões a ele relacionadas, com proporções e intensidades diferentes, a depender das diferenças individuais, mesmo frente a complexas mudanças no ambiente de trabalho. Grupos e indivíduos podem diferir quanto à intensidade com que se vinculam às atividades, ao passo que a organização também pode encaminhar seus funcionários a terem diferentes níveis de vínculo, identificação ou apropriação dos valores organizacionais, normas e princípios (Siqueira \& Gomide, 2004).

O comprometimento, em termos de vocábulo, refere-se ao ato de comprometer-se com algo, incluindo uma noção de obrigação em virtude de compromisso (Siqueira \& Gomide, 2004). Numa concepção genérica, trata-se de um vínculo estabelecido entre o trabalhador e a organização de trabalho, cuja natureza unidimensional ou multidimensional é alvo de divergência entre pesquisadores (Borges \& Albuquerque, 2014). As dimensões mais estudadas e acolhidas pelos pesquisadores são o comprometimento organizacional afetivo, calculativo, instrumental, de continuação e normativo.

O comprometimento organizacional apresenta-se como um fenômeno com três componentes de vínculo: O desejo (comprometimento afetivo), a necessidade (comprometimento instrumental, de continuação ou calculativo) e a obrigação moral (comprometimento normativo). O comprometimento afetivo é entendido como um apego à organização, resultante de experiências anteriores que promovem sensação confortável dentro da organização e competência no trabalho. A dimensão instrumental envolve a avaliação dos custos associados à saída da organização, tomando por base a magnitude do número de investimentos feito pelo empregado na organização e a falta de alternativas no mercado, enquanto o comprometimento normativo consiste na adesão às normas e objetivos da organização, a partir de pressões normativas internalizadas pelos trabalhadores que ocorrem no processo de socialização após a entrada na organização. Deste modo, um estado psicológico de comprometimento organizacional seria uma combinação desses três componentes em diferentes níveis de intensidade (Bastos et al., 2011; Bastos et al., 2014).

De um modo geral, o comprometimento pode ser entendido como o forte vínculo do trabalhador com a organização na qual está inserido e com aspectos relacionados a outras dimensões de sua vida como, por exemplo, o trabalho, a carreira, o sindicato, a profissão, entre outros, que produz uma noção de lealdade (Bandeira, Marques, \& Veiga, 2000).

A pesquisa sobre o comprometimento organizacional leva a um conjunto de variáveis que o antecedem, incluindo variáveis pessoais, características do trabalho, experiências e características da organização (Jaros, 2007). Os estudos versam, geralmente, sobre o comprometimento aplicado a organizações da iniciativa privada. A administração pública direta tende a percorrer um trajeto mais longo para atingir graus significativos de comprometimento organizacional, podendo-se atribuir essa morosidade a estilos de gestão autoritários, ausência de política de gestão de pessoas fundamentada em mérito e também a uma política salarial que não consegue reter pessoas com melhores qualificações, gerando atitude 
negativa frente ao trabalho (Lizote, Verdinelli, \& Nascimento, 2017). O presente estudo configura uma investigação em organização pública, com vistas a analisar a influência da socialização organizacional sobre o comprometimento organizacional de policiais militares do estado de Sergipe.

\subsection{Contextualização sobre o campo de pesquisa}

A história das polícias militares no Brasil começa na época do Império, quando foram criadas para a defesa dos interesses de grupos conservadores, em virtude da construção da estrutura social e política brasileira da época. A Polícia Militar (PM) foi concebida com uma gestão fundamentada na hierarquia e no valor às patentes, e suas ações são de cunho disciplinador e repressivo. As práticas de comando das organizações militares foram institucionalizadas conforme normas e valores internos e são repassadas de geração para geração, modelando o comportamento dos indivíduos, sua identidade e valores, conforme o interesse da gestão da organização. Assim, elementos como disciplina e hierarquia configuram-se como princípios da doutrina que fundamenta a PM como organização e, à medida que o policial ascende na hierarquia, consequentemente, sua autoridade e responsabilidade também aumentam. Sendo assim, considera-se imprescindível o respeito à autoridade hierárquica, às leis, normas e regulamentos que orientam o funcionamento da corporação (Rodrigues, 2010).

A socialização organizacional dos novos policiais começa na academia de polícia, pela transmissão de conhecimentos e habilidades técnicas, e continua na própria unidade de lotação, com a aprendizagem sobre o cotidiano de trabalho. Porém, é no campo afetivo que se encontra o principal objetivo de uma academia militar no que tange à socialização organizacional. É através da internalização do éthos militar que os novos policiais forjarão sua identidade profissional, pela assimilação de valores, símbolos, discursos e padrões de conduta típicos da cultura militar, os quais os capacitarão, de fato, para o desempenho de seu papel na organização. Assim, o processo de socialização ultrapassa as dimensões de um simples treinamento para tentar abranger a experiência subjetiva dos indivíduos (Wortmeyer, 2007).

A história da PM do estado de Sergipe, segundo informações do website da PM-SE (seção "Origem e Formação”), iniciou-se com a Força Policial da Província, há 178 anos. Atualmente, a estrutura da PM-SE é composta por: Comando Geral, pelo Estado Maior, oito Batalhões por todo o estado (três em Aracaju, a capital, $1^{\circ}, 5^{\circ}$ e $8^{\circ}$ Batalhões da Polícia Militar, e cinco no interior, os $2^{\circ}, 3^{\circ}, 4^{\circ}, 6^{\circ}$ e $7^{\circ}$ Batalhóes da Polícia Militar), Batalhão Especial de Segurança Patrimonial (BESP), Batalhão de Operações Especiais (BOPE), Batalhão de Policiamento de Guardas (BPGd), Hospital da PM, Centro de Formação e Aperfeiçoamento de Praças, Esquadrão de Polícia Montada, Companhia de Polícia Rodoviária Estadual, Companhia de Polícia de Trânsito, Batalhão de Polícia de Choque, Companhia de Polícia Fazendária, Companhia de Polícia Escolar, Companhia de Polícia de Radiopatrulha e Pelotão de Polícia Ambiental, além de 10 Companhias de Polícia Comunitária.

\section{Procedimentos Metodológicos}

\subsection{População e Amostra}

A população do presente estudo consistiu em servidores da PM-SE (Praças/Graduados e Oficiais) de quatro batalhões ou companhias de polícia especializada:

1) Companhia de Polícia de Trânsito (CPTran);

2) Batalhão de Polícia de Choque (BPChq);

3) Companhia de Polícia Rodoviária Estadual (CPRv);

4) Companhia de Polícia de Radiopatrulha (CPRp). 
O Praça é um militar que pertence à categoria de nível hierárquico inferior na Corporação Militar, com exigência de nível fundamental, médio e médio-técnico de escolaridade. O graduado consiste no grau hierárquico do Praça, incluindo o Primeiro, Segundo e Terceiro-Sargento e o Cabo. O Oficial constitui o membro investido numa posição de autoridade e está habilitado a exercer o comando de unidades.

Os critérios de inclusão na amostra foram: Ser servidor ativo da PM-SE (não estar aposentado ou afastado do serviço por motivos de doença ou acidente de trabalho), possuir escolaridade a partir do ensino médio e ter concluído o curso de formação (no caso de Praças, o curso técnico de Segurança Pública, e, no caso de Oficiais, o curso de bacharelado em Segurança Pública).

Participaram do estudo 270 servidores, dos quais $24,1 \%$ eram oriundos da CPTran, 25,9\% provinham do BPChq, 25,2\% da CPRp e 24,8\% da CPRv, indicando distribuição equilibrada da amostra. A maioria dos respondentes foi do sexo masculino (93,7\%), com ensino superior incompleto $(27,6 \%)$ ou completo $(25,0 \%)$, casado $(67,7 \%)$ e com 2 (dois) filhos (34,7\%). Os participantes desempenham função operacional $(77,2 \%)$ ou administrativa $(22,8 \%)$.

A amostra foi composta, em sua maioria, por Soldados (50,4\%) e Cabos (21,5\%). Não houve participação de nenhum oficial de maior graduação. A média de idade dos respondentes foi de 37 anos $(d p=5,74)$, variando de 24 a 51 anos. O tempo médio na organização foi de 182,54 meses $(d p=76,75)$, o que corresponde a, aproximadamente, 15,22 anos. O tempo médio na atual função foi de 97,49 meses $(d p=$ $77,90)$, correspondente a 8,12 anos. A renda individual média dos respondentes foi de $\mathrm{R} \$ 4.020,40$ ( $d p=\mathrm{R}$ $\$ 1.101,30)$ e a média da renda familiar apresentou-se em $\mathrm{R} \$ 5.350,43(d p=\mathrm{R} \$ 2.219,52)$.

\subsection{Instrumentos para coleta de dados}

1) Inventário de Socialização Organizacional (Borges, Silva, Melo, \& Oliveira, 2010), com 45 itens que mensuram, através de sete fatores $\left(\mathrm{KMO}=0,92 ; \mathrm{r}^{2}=47,68 \%\right)$, as características e a magnitude da percepção sobre sua socialização organizacional por parte do empregado. Os fatores são: 1) Acesso a Informações (Políticas) $(\alpha=0,78) ; 2)$ Competência e Proatividade $(\alpha=0,81) ; 3)$ Integração com as Pessoas $(\alpha=0,81) ; 4)$ Não Integração com a Organização $(\alpha=0,70) ; 5)$ Qualificação Profissional $(\alpha=0,71) ; 6)$ Objetivos e Valores Organizacionais $(\alpha=0,81)$; 7) Linguagem e Tradição $(\alpha=0,83)$. As respostas estavam dispostas em escala Likert de concordância com 5 (cinco) pontos, variando desde forte discordância a forte concordância.

2) Escala de Comprometimento Organizacional (Bastos et al., 2011), com 22 itens distribuídos de forma a mensurar três dimensões (KMO $\left.\left.=0,93 ; \mathrm{r}^{2}=40,19\right): 1\right)$ Afetiva $\left.(\alpha=0,88) ; 2\right)$ Instrumental $\left.(\alpha=0,80) ; 3\right)$ Normativa $(\alpha=0,76)$. As respostas são dadas em escala de 6 (seis) pontos, cujos extremos variam de discordo totalmente a concordo totalmente.

3) Ficha de dados sociodemográficos, contendo informações sobre o tempo de trabalho na organização, sexo, idade, escolaridade, estado civil, número de filhos, patente/graduação, função, tempo na função, rendas individual e familiar mensais.

\section{3 Procedimentos para coleta e análise dos dados}

Os dados da pesquisa foram coletados de forma presencial e auto aplicada em batalhões e companhias de polícia especializadas da PM-SE. Inicialmente, buscou-se autorização da PM-SE para a realização da pesquisa (liberação dos servidores para participação na pesquisa e do espaço físico para aplicação dos instrumentos). Os participantes foram convidados a assinar o Termo de Consentimento Livre e Esclarecido (TCLE), o qual continha informações sobre a pesquisa, incluindo os objetivos e contatos das pesquisadoras. A aplicação do instrumento aconteceu de forma coletiva, em grupos de, pelo menos, 10 servidores selecionados 
por conveniência, ou seja, os servidores que se encontravam em plantão de trabalho no dia da visita das pesquisadoras.

Para análise dos dados, utilizou-se o programa estatístico SPSS (Statistical Package for the Social Sciences), versão 20.0. Os dados foram inspecionados quanto a erros de digitação, dados faltosos e casos extremos, de maneira a preparar o banco de dados para análises multivariadas. Foram realizadas estatísticas descritivas (medidas de tendência central, dispersão e frequência) para caracterizar a amostra. O Inventário de Socialização Organizacional foi submetido à Análise Fatorial Exploratória (AFE), análise paralela (AP) e análise de consistência interna. A Escala de Comprometimento Organizacional também foi investigada quanto à consistência interna. Salientamos que esta escala não foi submetida à análise fatorial exploratória, em virtude de diversas evidências empíricas do modelo tridimensional de comprometimento organizacional. Adicionalmente, os dados foram submetidos aos testes inferenciais correlação de Pearson e análise de regressão múltipla com método stepwise.

\section{Resultados}

Os resultados referentes ao construto socialização organizacional derivam de AFE, AP, análise de consistência interna (alfa de Cronbach) e cálculos descritivos.

$\mathrm{O}$ teste de adequação da amostra, com $\mathrm{KMO}=0,83$, e o Teste de Esfericidade de Bartlett ( $\chi^{2}(990)$ $=3511,33 ; \mathrm{p}<0,001)$ comprovaram a fatorabilidade do Inventário de Socialização Organizacional. A solicitação de solução inicial por meio de extração dos componentes principais (Principal Component Analysis [PC]) apontou a possibilidade de retenção de até 13 componentes pelo critério de eingenvalue $\geq$ 1, contabilizando $63,84 \%$ de variância explicada. O gráfico Scree Plot sinalizava para a existência de quatro fatores.

Efetuou-se a AP e, pelo critério de Horn (1965), recomendou-se a possibilidade de aceitar seis fatores. Conforme recomendado em Borges et al. (2010), empreendeu-se análise fatorial dos eixos principais (Principal Axis Factoring [PAF]), rotação oblíqua, solicitação de sete fatores e critério de carga fatorial acima de 0,30 para manutenção do item, contudo, esta solução fatorial falhou na produção da matriz de cargas rotadas, assim como desaconselhou a retenção de sete fatores pelo critério de eingenvalue $\geq 1$. Alterou-se o método de rotação para ortogonal e, embora esta solução tenha possibilitado a saída da matriz de cargas rotadas, vários itens saturavam concomitantemente em mais de um fator, prejudicando a interpretação dos fatores.

Investigou-se a possibilidade de várias soluções fatoriais utilizando extração PC ou PAF, rotação ortogonal, cargas fatoriais entre 0,30 e 0,45 , desde solicitação de seis fatores até a possibilidade de uma solução unidimensional. Tais soluções, em geral, apresentavam problemas de dubiedade na interpretação dos fatores resultantes. Por fim, optou-se pela solução mais parcimoniosa, alcançada por meio de extração dos componentes principais com rotação ortogonal, critério de carga fatorial acima de 0,45 e estipulação de três fatores $\left(\mathrm{r}^{2}=33,12 \%\right)$. Permaneceram 24 itens na escala, distribuídos de acordo com a Tabela 1. 
Tabela 1 - Estrutura fatorial, coeficientes de confiabilidade e escores alcançados pela amostra em socialização organizacional

\begin{tabular}{|c|c|c|c|c|c|c|c|}
\hline Fatores & Definiçăo & $r^{2}$ & Eingenvalue & Número de itens & $\alpha$ & $M$ & $D p$ \\
\hline 1. Integraçăo à organizaçăo (IORG) & Percepçăo de integraçăo aos objetivos & $23,01 \%$ & 10,35 & 7 & 0,74 & 3,35 & 0,65 \\
\hline $\begin{array}{l}2 \text { 2. Dominio de procedimentos e } \\
\text { atividades (DPA) }\end{array}$ & $\begin{array}{l}\text { Percepcăo de dominio da linguagem } \\
\text { organizacional, de normas e de } \\
\text { procedimentos de trabalho. }\end{array}$ & $5,38 \%$ & 2,42 & 9 & 0,78 & 4,17 & 0,55 \\
\hline 3. Proatividade e competência (P\&C) & $\begin{array}{l}\text { Percepçăo de iniciativa própria na } \\
\text { busca por informaçóes ena persecuçăo } \\
\text { do bom desempenho laboral. }\end{array}$ & $4,73 \%$ & 2,13 & 8 & 0,78 & 4,03 & 0,55 \\
\hline
\end{tabular}

Este estudo não teve a pretensão de realizar análise fatorial confirmatória, visto que não está entre seus objetivos o teste do modelo teórico para socialização organizacional, portanto, estes resultados disponibilizam uma alternativa de estrutura fatorial para o ISO, embora sejam necessárias análises confirmatórias para decidir a estrutura que permite melhor compreensão sobre o fenômeno.

Acerca dos escores em cada fator, percebe-se que os participantes concordam sobre sua socialização quanto aos aspectos técnicos de seu trabalho (Fator 2 - DPA $=4,17$ ) e ao seu investimento pessoal em direção a facilitar seu processo de socialização organizacional (Fator $3-\mathrm{P} \& \mathrm{C}=4,03$ ). Verificamos que a resposta média no Fator $1(\mathrm{IORG}=3,35)$ aproximou o posicionamento da amostra ao ponto neutro da escala (3), conduzindo-nos ao entendimento de que ou os participantes não quiseram emitir opinião sobre o assunto, ou não vivenciam aspectos pertinentes a este tipo de socialização.

Os resultados referentes ao comprometimento organizacional foram alcançados por meio de análise de consistência interna (alfa de Cronbach) e cálculos descritivos. A Escala de Comprometimento Organizacional alcançou excelente índice de confiabilidade $(\alpha=0,88)$. Os coeficientes alfa de Cronbach e escores da amostra em cada fator podem ser visualizados na Tabela 2, assim como a estrutura fatorial corroborada por Bastos et al. (2011).

Tabela 2 - Estrutura fatorial, coeficientes de confiabilidade e escores alcançados pela amostra em comprometimento organizacional

\begin{tabular}{|c|c|c|c|c|c|c|c|}
\hline 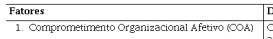 & & 20148 & Fingemolhe & $\begin{array}{l}\text { Nimmero de itens } \\
\frac{10}{10}\end{array}$ & 0 & (3,978 & $D_{1,12}$ \\
\hline 2 & 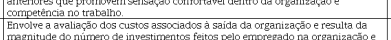 & $1277 \times$ & 2.94 & 7 & 0.72 & 3.77 & 0.98 \\
\hline $\begin{array}{lll}3 \\
3\end{array}$ & 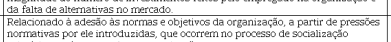 & $6.00 \%$ & 1.56 & 5 & 0.70 & 2.60 & 1.15 \\
\hline
\end{tabular}

Quanto aos escores da amostra em cada base de comprometimento, observa-se que os participantes se percebem pouco comprometidos de forma afetiva $(3,97)$ ou instrumental $(3,77)$ com a organização de trabalho. No que tange à base normativa, os participantes declararam discordar razoavelmente $(2,60)$ que se sintam implicados com a organização por motivos de ordem moral ou por pressão normativa do grupo. 
Foram realizadas correlações de Pearson para verificar em que medida a socialização e o comprometimento estavam associados e para orientar as futuras análises de regressão. Os três fatores de socialização organizacional correlacionam positivamente, com intensidades variando de fraca a moderada, com o comprometimento afetivo (IORG: $r=0,58, p<0,001$; DPA: $r=0,26, p<0,001 ; P \& C: r=0,44, p<0,001$ ). Quanto maior o grau de socialização organizacional percebida pelos respondentes, maior a relação afetiva com a PM-SE. O fator DPA relaciona-se inversamente com a dimensão instrumental de comprometimento organizacional $(\mathrm{r}=-0,14, \mathrm{p}=0,025)$, indicando que quanto maior o domínio dos procedimentos laborais, menor a percepção de prejuízo relacionado à saída da organização. O comprometimento normativo apresentou relação positiva com os fatores IORG $(r=0,32, p<0,001)$ e $P \& C(r=0,26, p<0,001)$, sugerindo que quanto mais o indivíduo se perceba integrado à organização e quanto mais ele colabore para a própria socialização, maior a aderência às normas e objetivos organizacionais.

Foram realizadas três análises de regressão múltipla, uma para cada base de comprometimento organizacional a ser explicada (COA, COI e CON). Em todas as análises utilizou-se método stepwise e como preditivos, variáveis sociodemográficas e ocupacionais (idade, renda individual, tempo na organização e tempo na função) e variáveis psicológicas (IORG, DPA e P\&C - fatores do constructo socialização organizacional).

A primeira análise de regressão considerou o comprometimento afetivo (COA) como variável critério. Foram gerados seis modelos explicativos, dos quais o modelo que agregou as variáveis preditivas IORG, $\mathrm{P} \& \mathrm{C}$, tempo na função e renda individual foi o que apresentou os melhores índices $\left[\mathrm{F}_{(4,233)}=45,46 ; \mathrm{p}<0,001\right]$, conforme Tabela 3.

Tabela 3 - Resultados de análise de regressão múltipla para a base afetiva de comprometimento organizacional

\begin{tabular}{|c|c|c|c|c|c|c|c|c|}
\hline Base & $R$ & $R^{2}$ & $R^{2}$ ajustado & $\begin{array}{l}\text { Erro padrão da } \\
\text { estimativa }\end{array}$ & Preditores & B & $T$ & $P$ \\
\hline \multirow[t]{4}{*}{$\mathrm{COA}$} & \multirow[t]{4}{*}{0,66} & \multirow[t]{4}{*}{0,44} & \multirow[t]{4}{*}{0,43} & \multirow[t]{4}{*}{0,85} & IORG & 0,43 & 7,44 & $<0,001$ \\
\hline & & & & & $\mathrm{P} \& \mathrm{C}$ & 0,19 & 3,29 & $=0,001$ \\
\hline & & & & & Tempo na função & 0,20 & 3,97 & $<0,001$ \\
\hline & & & & & Renda individual & 0,19 & 3,65 & $<0,001$ \\
\hline
\end{tabular}

Todos os pesos $\beta$ f oram positivos, indicando a inexistência de relações inversas entre as variáveis. Os preditivos reúnem um bom percentual de variância explicada (44\%) para COA. O preditivo que mais contribui para a determinação do comprometimento afetivo é o fator ligado à integração à organização. As variáveis relacionadas ao tempo na organização, à idade e ao DPA não colaboraram para explicar comprometimento afetivo nesta análise de regressão.

Executou-se nova análise de regressão, desta vez utilizando o comprometimento instrumental (COI) como variável critério. Foi gerado apenas um modelo explicativo, no qual a variável relacionada à idade figurava como única preditiva $\left[\mathrm{F}_{(1,236)}=5,55 ; \mathrm{p}=0,02\right]$, explicando $2 \%$ da variância do comprometimento instrumental. As variáveis relacionadas a tempo na organização, tempo na função, renda individual, IORG, DPA e P\&C não contribuíram na explicação de COI (Tabela 4).

Tabela 4 - Resultados de análise de regressão múltipla para a base instrumental de comprometimento organizacional

\begin{tabular}{l|l|l|l|l|l|l|l|l}
\hline Base & $\boldsymbol{R}$ & $\boldsymbol{R}^{2}$ & $\begin{array}{l}\boldsymbol{R}^{2} \\
\text { ajustado }\end{array}$ & $\begin{array}{l}\text { Erro padrão da } \\
\text { estimativa }\end{array}$ & Preditores & B & $\boldsymbol{T}$ & $\boldsymbol{P}$ \\
\hline COI & 0.15 & 0.02 & 0.02 & 0.98 & Idade & 0.15 & 2.36 & $=$
\end{tabular}


Por fim, a análise de regressão que usou como critério o comprometimento normativo (CON) gerou quatro modelos explicativos, dos quais aquele que reuniu as variáveis preditivas relacionadas com a idade, IORG, tempo na função e P\&C foi considerado mais promissor $\left[F_{(4,233)}=17,70 ; p<0,001\right]$, conforme Tabela 5. Nesta equação de regressão, a variável de maior determinação sobre CON é "idade", ainda que o percentual de variância explicada pelos preditivos em conjunto seja baixo (23\%). As variáveis ligadas a tempo na organização, renda individual e DPA ficaram fora do modelo explicativo.

Tabela 5 - Resultados de análise de regressão múltipla para a base normativa de comprometimento organizacional

\begin{tabular}{|c|c|c|c|c|c|c|c|c|}
\hline Base & $R$ & $R^{2}$ & $R^{2}$ ajustado & $\begin{array}{l}\text { Erro padrão da } \\
\text { estimativa }\end{array}$ & Preditores & B & $T$ & $P$ \\
\hline \multirow[t]{4}{*}{$\mathrm{CON}$} & \multirow[t]{4}{*}{0,48} & \multirow[t]{4}{*}{0,23} & \multirow[t]{4}{*}{0,22} & \multirow[t]{4}{*}{1,02} & Idade & 0,26 & 4,17 & $<0,001$ \\
\hline & & & & & IORG & 0,19 & 2,89 & $=0,004$ \\
\hline & & & & & Tempo na função & 0,16 & 2,67 & $=0,008$ \\
\hline & & & & & $\mathrm{P} \& \mathrm{C}$ & 0,13 & 1,99 & $=0,048$ \\
\hline
\end{tabular}

\section{Discussão}

Para mensurar socialização organizacional, utilizou-se o Inventário de Socialização Organizacional - ISO (Borges et al., 2010). Observou-se a necessidade de realização de investigação de validade e confiabilidade da medida, considerando as poucas evidências de suas propriedades psicométricas. A AFE não corroborou a estrutura fatorial proposta pelos autores, fornecendo solução alternativa para a dimensionalidade do construto. A realização de novas investigações comparativas acerca da adequação das estruturas internas propostas por este estudo e por Borges et al. (2010) é tarefa imprescindível para futuras pesquisas.

Os escores médios da amostra apontam possível predominância do fator Domínio de procedimentos e atividades $(\mathrm{DPA}=4,17)$ sobre os demais fatores, caracterizando a assunção pelos respondentes de uma socialização de cunho mais técnico. A definição constitutiva do fator IORG traduz uma socialização de natureza cultural e as respostas da amostra próximas à neutralidade neste quesito levantam os seguintes questionamentos: Será que não existem ações voltadas para a socialização cultural na instituição estudada que subsidiem a percepção e o julgamento pelo funcionário sobre o quanto este se percebe integrado ao ambiente de trabalho, ou, por razões outras, o indivíduo simplesmente se evadiu de apresentar sua opinião?

Buscando esclarecimento para tal resultado, o que se sabe sobre os cursos de formação da PM-SE encaminha ao entendimento de que existem ações tanto de socialização técnica, quanto cultural, nestes eventos. Trata-se de um processo de socialização organizacional institucionalizado, com metodologia de socialização fundamentada em base social em detrimento de base multimídia, e que se inicia com o Curso de Formação de Praças ou Curso de Formação de Oficiais (Wesson \& Gogus, 2005). A dúvida que resta é se o tempo definido para o curso de formação é suficiente para que os servidores assumam uma identidade profissional policial e estejam plenamente adaptados à cultura militar.

Os itens que saturaram no fator IORG abrangem também as relações interpessoais e de confiança e a participação nas decisões da organização, o que nos leva a pensar que os servidores optaram por não se posicionar sobre tais questões. Talvez o fato de trabalhar numa organização caracterizada por uma filosofia militar desmotive o estabelecimento de relações interpessoais mais francas e demonstrações mais democráticas de inserção nas questões do trabalho.

$\mathrm{O}$ fator Proatividade e Competência $(\mathrm{P} \& \mathrm{C}=4,03)$ foi o segundo maior escore. $\mathrm{O}$ posicionamento dos respondentes mostrou iniciativa própria no sentido de gerir sua socialização na organização. Esta atitude não 
é unicamente dependente de características de personalidade ou de disposição, ela pode ser despertada por meio dos cursos de formação de Praças e de Oficiais, os quais são ações institucionalizadas para o processo de socialização, mas que também exigem do aluno certo esforço autodidata para adequar-se às normas e à linguagem oficial, podendo ser um estímulo à busca por disciplina própria e em grupo e à adoção de uma postura militar. A diligência pessoal nesta empreitada colabora para a construção de um conhecimento particular sobre em que consiste o trabalho que o indivíduo desenvolve, quais as expectativas em torno do seu papel no grupo e qual a identidade organizacional.

Quanto ao comprometimento organizacional, os índices foram baixos tanto na base afetiva $(\mathrm{M}=$ 3,97) quanto na instrumental $(\mathrm{M}=3,77)$, indicando que os participantes se percebem apenas um pouco comprometidos com a organização. Os resultados frágeis de comprometimento organizacional encontrados no presente estudo corroboram os resultados da pesquisa de Bastos e Borges-Andrade (2002), os quais indicam que os padróes de comprometimento, em contextos de trabalho de natureza burocrática e tradicional, se expressam mais fragilmente.

O comprometimento instrumental versa sobre a avaliação da relação custo-benefício em permanecer na organização. Altos escores nesta dimensão significam que o indivíduo julga que as perdas objetivas decorrentes de sua saída da organização são maiores que os ganhos, conduzindo ao abandono de sua intenção de desligamento. Os participantes desta pesquisa parecem não vivenciar esta condição, fato curioso, uma vez que a remuneração da PM-SE é uma das melhores do Brasil (em torno de $\mathrm{R} \$ 3.300,00$ mensais para a patente de soldado) e dificilmente o policial encontraria remuneração equivalente ou superior na iniciativa privada.

O comprometimento afetivo também foi baixo. Esta dimensão corresponde ao apego e sentimentos dirigidos à organização: o indivíduo se identifica com a mesma e gosta de trabalhar nela. Aventamos que a explicação para o quadro de pouco comprometimento afetivo seja a inexistência de trocas sociais equânimes entre o servidor e a instituição, no que tange à liberdade de participação na gestão de processos e nas políticas corporativas. Suspeita-se que esta dimensão do comprometimento, no grupo pesquisado, possa estar mais dirigida à equipe operacional na qual o servidor se encontra, considerando que os valores de coletividade entre os pares são fortemente valorizados dentro das corporações. A lealdade é concebida como uma forma de relacionamento que implica transparência e comprometimento com o outro e propicia a emergência da confiança mútua. $\mathrm{O}$ contexto de realização de diversas atividades em conjunto, que implicam interdependência entre os pares, reforçam a consciência grupal e a internalização da lealdade (Wortmeyer, 2007). Contudo, o aspecto de comprometimento com a equipe de trabalho não foi investigado nessa pesquisa, sugerindo-se que os próximos estudos verifiquem esta hipótese.

Quanto ao comprometimento normativo, o resultado $(M=2,60)$ indicou que se percebem razoavelmente descomprometidos. O comprometimento normativo congrega um vínculo à organização baseado em obrigação moral ou coerção normativa do grupo. Os participantes investigados tanto não se veem normativamente comprometidos à organização, quanto aparentam não ceder às pressões corporativas. Uma tentativa de explicação para este resultado remonta à luta associativa destes militares, corroborando o que Silva e Vieira (2008) ressaltam: uma vez que ao militar não é permitida a participação em greve, o servidor da PM se vale de outros meios de reivindicação por melhorias de condições de trabalho e de salário. Especificamente na PM de Sergipe, durante a realização da pesquisa, ocorria um vigoroso movimento reivindicatório (eminentemente constituído por praças) em prol da defesa de direitos. Tal movimento sustentava uma resistência organizada a determinações organizacionais percebidas como indevidas, aviltantes ou nocivas. Para fins de discussão deste resultado, apresentamos outro cenário organizacional militar em que o contexto social comparecia de forma diametralmente oposta.

O processo de socialização levado a cabo no contexto organizacional militar investigado por Wortmeyer (2007) caracterizou-se pelo exercício de intenso controle sobre os sujeitos, enfatizando o disciplinamento. Desde o primeiro dia de sua formação, os cadetes deveriam aprender a se ajustar às normas de conduta e a se comportarem de forma padronizada, seguindo fielmente os regulamentos. Para tanto, eram constantemente 
orientados e fiscalizados por seus superiores, que efetuavam correções e aplicavam sanções quando ocorriam desvios do padrão de comportamento valorizado. Pretendia-se, com este processo socializador, potencializar a internalização de normas. Tendo este quadro para fins de comparação, acredita-se que a vivência inusitada de um ambiente de contestação e crítica aos valores de disciplina e obediência militares, que a PM-SE estava vivenciando quando da época da presente pesquisa, não providenciava terreno fértil para o desenvolvimento da base normativa do comprometimento. Acreditamos que, no lugar de um vínculo moral com a organização, o que comparece é um engajamento em causas pessoais e da categoria.

O fator Integração à organização apresentou-se como o principal preditivo do comprometimento afetivo dos respondentes. A integração com a organização pode ser potencializada pelo acolhimento da organização e dos colegas de trabalho, pela confiança inspirada pelo ambiente laboral, por meio da acessibilidade aos diversos serviços da organização, por exemplo. Os escores da amostra nesta dimensão da socialização organizacional foram inconcludentes, em virtude de terem se aproximado da neutralidade, deixando uma lacuna acerca dos motivos que levaram os respondentes a não emitirem opinião e denunciando um elemento estratégico que está deixando de ser aproveitado pela instituição.

Dentre outras variáveis preditivas do vínculo afetivo, a variável denominada Proatividade e Competência indica um esforço individual desse servidor em conhecer a organização, adaptar-se, socializar-se à mesma, como também um esforço em desempenhar bem seu trabalho, colaborando para que se apegue ainda mais à razão do seu esforço.

O comprometimento instrumental foi explicado apenas pela variável relacionada à idade do grupo pesquisado, a qual contribui debilmente $\left(\mathrm{r}^{2}=2 \%\right)$ para sua compreensão. Aparentemente, o processo de socialização organizacional não é decisivo na ponderação calculada sobre os custos-benefícios em se desligar da organização, aspecto este que, provavelmente, estaria mais relacionado a questóes materiais da existência do indivíduo ou a critérios de avaliação e recompensa na empresa.

A variável que mais determina o comprometimento normativo é a idade: conforme a idade avança e incrementam-se as responsabilidades atreladas aos papéis sociais, verifica-se que as pessoas se inclinam para um perfil mais normativo (Gouveia, Fonsêca, Milfont, \& Fischer, 2011), o mesmo podendo acontecer na situação laboral. Os fatores relacionados à socialização organizacional, Integração à organização e Proatividade e competência também repercutem no comprometimento normativo. A sensação de maior pertencimento ao grupo e a busca ativa por se adaptar ao contexto de trabalho e às tarefas do cargo conduzem à adesão às normas de funcionamento e especificidades da instituição. Tais resultados se aproximam dos estudos de Meyer, Stanley, Herscovitch e Topolnytsky (2002), que apontam a socialização organizacional como antecedente do comprometimento normativo. Ressaltamos que na presente pesquisa, pelo menos dois dos três fatores de socialização organizacional apresentam-se entre os preditivos dessa dimensão de comprometimento.

Sintetizando os achados desta pesquisa, o comprometimento instrumental não sofreu influência da socialização organizacional. Os fatores de socialização que foram determinantes na predição do comprometimento não incluem a dimensão relacionada ao Domínio de procedimentos e atividades. São a socialização cultural (capitaneada pela instituição) - fator IORG - e a socialização movida pelo próprio indivíduo - fator $\mathrm{P} \& \mathrm{C}$ - que produzem efeito sobre os vínculos positivos (afetivo e normativo) com sua organização de trabalho.

Cumpre destacar que o processo de socialização na cultura militar apresenta um caráter pedagógico, de natureza formal, com elementos disciplinares e coercitivos, que visam à transformação de um civil em militar (Rosa \& Brito, 2010). Considerando essa característica, pode-se esperar que comprometimento organizacional seja independente dos processos de socialização nas organizações militares, sendo originado, basicamente, por aspectos coercitivos característicos da filosofia destas instituições. No entanto, o comprometimento organizacional se trata de um vínculo psicossocial entre o indivíduo e sua organização de trabalho, de modo que o fenômeno encontra-se também no campo dos afetos, isto é, precisa ser estimulado 
pela organização contratante (jamais coagido) e vivenciado de forma genuína pelos membros de uma organização (Bastos et al., 2014). As pressões coercitivas não geram comprometimento afetivo, pois seu teor opressivo contraria a lógica de formação de vínculos afetivos constituintes desta base. Já programas de socialização organizacional bem planejados e executados suscitam a mobilização de afetos positivos e construção de crenças e normas sociais coerentes com a cultura organizacional.

Por fim, pontua-se que os resultados desta pesquisa reafirmam a importância do cuidado institucional com o processo de socialização dos seus funcionários, a importância de conhecer como este ocorre e como pode ser facilitado, a reflexão sobre a flexibilização deste processo para que a iniciativa do indivíduo tenha lugar garantido na sua socialização. No caso específico da PM de Sergipe, melhorias no processo de socialização organizacional podem ser implementadas pelo CFAP em parceria com todas as demais instâncias da organização.

\section{Considerações FinAIS}

Frente aos desafios impostos pelo mundo do trabalho, a Psicologia Organizacional e do Trabalho vem buscando aprofundamento no estudo das questões que envolvem o trabalhador, os grupos e as organizações, no sentido de contribuir para uma melhor atuação dos profissionais da área. Assim, o presente estudo teve como objetivo analisar a influência da socialização organizacional sobre o comprometimento organizacional dos servidores de unidades especializadas da PM-SE.

Os resultados foram satisfatórios, indicando influência de dois fatores da socialização organizacional (IORG e P\&C) em duas dimensões do comprometimento organizacional (afetiva e normativa). Estes achados revelam a importância do investimento em ações que contribuam com o processo de socialização organizacional, especialmente ações voltadas para a percepção e compreensão da cultura organizacional, dos objetivos, relacionamento interpessoal, ações que facilitem o acesso às informações importantes, possibilitando que o funcionário também busque sua própria socialização e desenvolva competências.

Identificamos como limitações a especificidade do campo de pesquisa, que limita a possibilidade de comparação com outras organizações públicas, como também com as organizações privadas. Quanto à elucidação do comprometimento instrumental, as variáveis trabalhadas não geraram esclarecimento. Além disso, o caráter interveniente do tempo de organização não foi investigado. Sugerimos, portanto, que em novas pesquisas essa variável seja controlada.

Diante do exposto, faz-se importante a realização de novos estudos sobre socialização organizacional, em que pese a realização de uma análise confirmatória da alternativa de estrutura fatorial aqui encontrada. Quanto ao comprometimento, seguimos a recomendação da literatura (Bastos et al., 2014) acerca da necessidade de que os estudos sejam ampliados para vínculos de diferentes focos (comprometimento com o trabalho e com a equipe, por exemplo), a fim de evitar a quase hegemônica produção voltada ao foco organizacional.

Em virtude de a PM ser uma organização com cultura marcada pela hierarquia e disciplina, após a formação do Praça e do Oficial e efetivação no serviço (início das atividades laborais), a socialização continua sendo acompanhada e analisada? Os profissionais recebem feedback sobre seu desempenho e também se colocam sobre como percebem sua socialização? Estes são alguns questionamentos que podem gerar futuras pesquisas na área.

Salientamos ainda que, ao se perceber desempenho dos novos funcionários aquém das expectativas organizacionais, em geral, pode-se levantar questionamentos sobre o processo seletivo. Esses questionamentos tendem a buscar fragilidades em critérios e técnicas utilizadas que possam esclarecer os motivos da não adaptação do novo funcionário à organização e ao trabalho. Sugerimos migrar o olhar para o período pós-seletivo do novo funcionário, de forma que se investigue, por exemplo, se o descompasso 
vivenciado pelo mesmo compreende fatores relacionados à fase inicial das atividades de trabalho, à inserção na outra cultura organizacional ou ao acompanhamento do seu processo de socialização organizacional.

\section{REFERÊNCIAS}

Allen, T. D., Eby, L. T., Chao, G. T., \& Bauer, T. N. (2017). Taking stock of two relational aspects of organizational life: Tracing the history and shaping the future of socialization and mentoring research.Journal of Applied Psychology, 102(3), 324-337.

Bandeira, M. L., Marques, A. L., Veiga, R. T. (2000). As dimensões múltiplas do comprometimento organizacional: um estudo na ECT/MG. Revista de Administração Contemporânea, 4(2), 133-157.

Bastos, A. V. B., Borges-Andrade, J. E. (2002). Comprometimento com o trabalho: Padrões em diferentes contextos organizacionais. Revista de Administração de Empresas, 42(2), 31-41.

Bastos, A. V. B., Maia, L. G., Rodrigues, A. C. A., Macambira, M. O., Borges-Andrade, J. E. (2014). Vínculos dos indivíduos com a organização: Análise da produção científica brasileira 2000-2010. Psicologia: Teoria e Pesquisa, 30(2), 153-162.

Bastos, A. V. B., Pinho, A. P. M., Aguiar, C. V. N., Menezes, I. G. (2011). Comprometimento organizacional: Aprimoramento e evidências de validade do modelo tridimensional de Meyer e Allen no contexto brasileiro. In: Zanelli, J. C., Silva, N., Tolfo, S. R. (Orgs.). Processos psicossociais nas organizaçôes e no trabalho. São Paulo: Casa do Psicólogo, p. 145-160.

Borges, L. O., Albuquerque, F. J. B. (2014). Socialização organizacional. In: Zanelli, J. C., Borges-Andrade, J. E., Bastos, A.V.B. (Orgs.). Psicologia, organizações e trabalho no Brasil. 2 ed. Porto Alegre: Artmed, p. 331-356.

Borges, L. O., Silva, F. H. V. C., Melo, S. L., Oliveira, A. S. (2010). Reconstrução e validação de um inventário de socialização organizacional. Revista de Administração Mackenzie (RAM), 11(4),4-37.

Bowditch, J. L., Buono, A. F. (2002). Elementos de comportamento organizacional. São Paulo: Pioneira Thompson.

Cardozo, B. D. A., Araújo, G. C. D., Mariani, M. A. P. (2017). Comprometimento organizacional em uma cooperativa de reciclagem. Interaçôes (Campo Grande), 18(3), 107-120.

Cardozo, B. D. A., Arriero, E. B., Mariani, M. A. P., Araújo, G. C., Arruda, D. O. (2018). A cultura organizacional nos processos de recrutamento, seleção e socialização em redes hoteleiras em Campo Grande, Mato Grosso do Sul, Brasil. Desafio Online, 6(1), 88-107.

Cooper-Thomas, H. D., Paterson, N. L., Stadler, M. J., Saks, A. M. (2014). The relative importance of proactive behaviors and outcomes for predicting newcomer learning, well-being, and work engagement. Journal of Vocational Behavior, 84(3), 318-331.

Carvalho, V. D., Borges, L. O., Vikan, A., Hjemdal, O. (2011). Resiliência e socialização organizacional entre servidores públicos brasileiros e noruegueses. Revista de Administração Contemporânea, 15(5), 815-833.

Dick, G. P. (2011). The influence of managerial and job variables on organizational commitment in the police. Public administration, 89(2), 557-576.

Genari, D., Ibrahim, C. V. D., Ibrahim, G. F. (2017). A percepção dos servidores públicos sobre a socialização organizacional: Um estudo no Instituto Federal de Educação, Ciência e Tecnologia do Rio Grande do Sul. HOLOS, 5(1), 313-328.

Gouveia, V. V., Fonsêca, P. N., Milfont, T. L., Fischer, R. (2011). Valores humanos: Contribuições e perspectivas teóricas. In: Torres, C. V., Neiva, E. R. (Orgs.). A psicologia social: Principais temas e vertentes. Porto Alegre: Artmed, p. 296-313.

Horn, J. L. (1965). A rationale and test for the number of factors in factor analysis. Psychometrika, 30(2),179-185.

Jaros, S. (2007). Meyer and Allen model of organizational commitment: Measurement issues. The Icfai Journal of Organizational Behavior, 6(4), 7-25.

Lizote, S. A., Verdinelli, M. A., Nascimento, S. (2017). Relação do comprometimento organizacional e da satisfação no trabalho de funcionários públicos municipais. Revista de Administração Pública, 51(6), 947-967. 
Meyer, J. P., Stanley, D. J., Herscovitch, L., Topolnytsky, L. (2002). Affective, continuance, and normative commitment to the organization: A meta-analysis of antecedents, correlates, and consequences. Journal of Vocational Behavior, 61(1), 20-52.

Miranda, A. R. A., Cappelle, M. C. A., Mafra, F. L. N., Moreira, L. B. (2015). Trabalho, socialização e identidade: um estudo com professoras gerentes de uma universidade pública. Avaliação: Revista da Avaliação da Educação Superior, 20(2).

Moyson, S., Raaphorst, N., Groeneveld, S., Van de Walle, S. (2018). Organizational socialization in public administration research: A systematic review and directions for future research. The American Review of Public Administration, 48(6), 610-627.

Oliveira, S. D. C., Lino, M. A. B., Borges, L. O, Carvalho, V. D., Melo, S. L., Silva, A. K. L., Steven, G. (2008). A socialização organizacional dos servidores da UFRN, segundo grupo ocupacional e tempo de serviço. Revista Psicologia: Organizaçôes e Trabalho, 8(1), 118-141.

Paiva, K. C. M., Dutra, M. R. S., Luz, T. R. (2015). Comprometimento organizacional de trabalhadores de call center. Revista de Administração, 50(3), 310-324.

Poncioni, P. (2005). O modelo policial profissional e a formação profissional do futuro policial nas academias de polícia do Estado do Rio de Janeiro. Sociedade e Estado, 20(3), 585-610.

Rodrigues, M. P. R. (2010). Gestão da polícia militar: a cultura institucional como agente limitador da construção de uma polícia cidadã. Dissertação de Mestrado, Fundação Getúlio Vargas, Rio de Janeiro, RJ.

Rodrigues, A. P. G., Bastos, A. V. B. (2013). Os vínculos de comprometimento e entrincheiramento presentes nas organizações públicas. Revista de Ciências da Administração, 15(36), 143-158.

Rosa, A. R., Brito, M. J. (2010). "Corpo e alma" nas organizações: um estudo sobre dominação e construção social dos corpos na organização militar. Revista de Administração Contemporânea, 14(2), 194-211.

Saks, A. M., Gruman, J. A. (2018). Socialization resources theory and newcomers' work engagement: a new pathway to newcomer socialization. Career Development International, 23(1), 12-32.

Silva, M. B., Vieira, S. B. (2008). O processo de trabalho do militar estadual e a saúde mental. Saúde Sociedade, 17(4), 161-170.

Silva, N., Zanelli, J. C. (2004). Cultura organizacional. In: Zanelli, J. C., Borges-Andrade, J. E., Bastos, A.V.B. (Orgs.). Psicologia, organizaçôes e trabalho no Brasil. Porto Alegre: Artmed, p. 407-442.

Siqueira, M. M. M., Gomide, S., Júnior (2004). Vínculos do indivíduo com o trabalho e com a organização. In: Zanelli, J. C., Borges-Andrade, J. E., Bastos, A.V.B. (Orgs.). Psicologia, organizaçôes e trabalho no Brasil. Porto Alegre: Artmed, p. 300-328.

Wesson, M. J., Gogus, C. I. (2005). Shaking hands with a computer: An examination of two methods of organizational newcomer orientation. Journal of Applied Psychology, 90(5), 1018-1026.

Woodrow, C., Guest, D. E. (2017). Leadership and approaches to the management of workplace bullying. European Journal of Work and Organizational Psychology, 26(2), 221-233.

Wortmeyer, D. S. (2007). Desafios da internalização de valores no processo de socialização organizacional: um estudo da formação de oficiais do Exército. Dissertação de mestrado, Programa de Pós-Graduação em Psicologia Social, Universidade do Estado do Rio de Janeiro, Rio de Janeiro, Brasil.

\section{BY-NC-ND}

